\title{
Monosynaptic reflexes in the superficial forearm flexors in man and their clinical significance
}

\author{
JACQUES DESCHUYTERE ${ }^{1}$, NOEL ROSSELLE, AND \\ CONSTANT DE KEYSER
}

From the Centre of Electromyography and Electrodiagnosis, Kliniek Heilige Familie, Antwerp, and the Department of EMG and Clinical Neurophysiology, University of Louvain, Louvain, Belgium

SYNOPSIS Indirect motor responses with the characteristics of the $\mathrm{H}$ wave were recorded from the flexor carpi radialis and the palmaris longus muscles in normal adults. A series of experiments has been performed, constituting circumstantial arguments for the monosynaptic nature of these reflex responses. The findings in pathological conditions, which corroborated this point of view, are documented briefly.

$\mathrm{H}$ reflexes have been studied extensively in man and it seems certain that group I nerve fibres subserve the monosynaptic reflex arc for the tendon tap as well as for the response evoked by submaximal electrical stimulation of the mixed nerve (Magladery et al., 1951). At variance with the postulations of Magladery et al. (1951), it was shown by Mayer and Feldman (1967) that $F$ waves were consistent with recurrent discharges. However, these authors stressed that, in the normal subject, the $F$ response consisted of a more complex potential and, with careful testing, that the $\mathrm{H}$ wave could be distinguished from the $F$ wave. Employing special techniques of facilitation, genuine monosynaptic reflex activity was demonstrated in the anterolateral muscles of the leg in normal adults by Deschuytere and Rosselle (1971), and measurements of the latencies of the reflex activity in the extensor digitorum longus muscle appeared to be very useful in studies of chronic fifth lumbar root compression syndromes (Deschuytere and Rosselle, 1973).

The present paper will document formerly presented (Deschuytere and Rosselle, 1974) and new arguments for the point of view that the indirect motor responses derived from the

\footnotetext{
${ }^{1}$ Address for correspondence and reprints: Dr J. Deschuytere, Provinciale steenweg 89, 2621 Schelle (Antwerp), Belgium.

(Accepted 18 February 1976.)
}

forearm flexor muscles may be considered as monosynaptic reflexes. Their clinical use (Deschuytere and Rosselle, 1975) is primarily concerned with measurements of latencies and the study of sinusoidal vibration of the tendon in respect of hyperreflexia.

\section{METHODS}

We examined 50 healthy adults, aged 18 to 64 years, who were without history or signs of neurological disease. The subjects lay in a supine position on a comfortable couch with the arm slightly abducted and with the elbow joint conveniently positioned at $35^{\circ}$ flexion. At times the hand was fixed firmly by tape to ensure isometric contraction. Reinforcement manoeuvres consisted of ipsilateral quadriceps muscle contractions, either isometric or with raising the leg (15 subjects). Electromyographic recording was carried out by coaxial needle electrodes inserted into the flexor carpi radialis muscle ( 20 subjects on both sides) and palmaris longus muscle. Electrical stimulation was performed either with bipolar surface electrodes or by a modified Simon electrode (Simon, 1962); in some individuals needle electrodes were used as well. Rectangular electric pulses of $1.0 \mathrm{~ms}$ duration were delivered by a stimulus isolation unit at a chosen strength. The median nerve was stimulated in the cubital fossa and in some subjects at the level of the axilla to prove the spinal origin of the late motor responses. Latencies were measured from the displayed stimulus artefact to the start of the evoked 
action potentials. Post-tetanic potentiation of the indirect motor responses, which was evaluated in five subjects, was obtained by a 200 per second repetition rate of the stimulus during 20 to 40 seconds. Such a stimulation was performed more proximally by means of a second isolation unit. In 15 subjects recovery curves were elaborated which necessitated paired stimuli of equal strength and identical duration. The equipment was a MS-3R Medelec apparatus with a fibre optic recorder and a separately mounted Polaroid camera. Tendon taps and blows at the styloid process of the radius were applied by means of a tapping device that triggered the sweep of the cathode ray oscilloscope. The effects of vibratory muscle stimuli on the secondary motor responses were studied in 30 subjects. The vibrator was an electromagnetic massage apparatus with a vibrating plate $2 \mathrm{~cm}$ in diameter, beating at a frequency of $100 \mathrm{~Hz}$ with an amplitude of 1 to $2 \mathrm{~mm}$ and/or a TVR HV-11 D vibrator (Heiwa Electronic Ind. Co., Ltd., Osaka, Japan). The pathological conditions studied will be described together with the results.

\section{RESULTS}

In every normal subject indirect motor responses (IMRs) were recorded from the flexor carpi radialis (FCR) muscle with an electrical stimulus (ES) intensity which was subliminal, liminal, slightly supraliminal, but always inframaximal for the direct motor responses (DMRs). Similar IMRs were derived from the palmaris longus (PL) muscle. When the stimulating electrode was moved proximally, the IMRs appeared with briefer latencies, indicating that the late motor responses were of central origin. In Fig. 1 recordings from the FCR muscle are demonstrated when percutaneous stimulation was performed using an ES intensity which was subliminal for the DMR. There are 10 superimposed recordings in both photographs, illustrating the stability of the IMRs latency. Small differences of the latencies were observed between the ipsi- and the contra-lateral side (less than $1.0 \mathrm{~ms}$ ). In different subjects the latencies ranged from 15 to $17 \mathrm{~ms}$ and were related to the height and the age of the person. As seen in the sequence of Fig. 2, an increasing intensity of the ES provokes a series of variations of the IMRs and DMRs comparable with what has been described for the soleus muscle. As the strength of the ES was increased the amplitude of the second motor response may enhance; when a small DMR wave occurred, the secondary motor discharges sometimes showed a slight increment together with an increasing DMR. A further enhancement of the stimulus intensity increased the amplitude of the DMR and concomitantly the amplitude of the IMR would decrease because the motor fibres of the nerve trunk became antidromically blocked. From the foregoing, it was evident that we were able to establish recruitment curves of the IMRs and DMRs as reported for the soleus muscle. Typical and representative recruitment curves of the IMR ( $H$ wave) and the DMR ( $M$ wave) derived from the FCR muscle are shown in Fig. 3. There

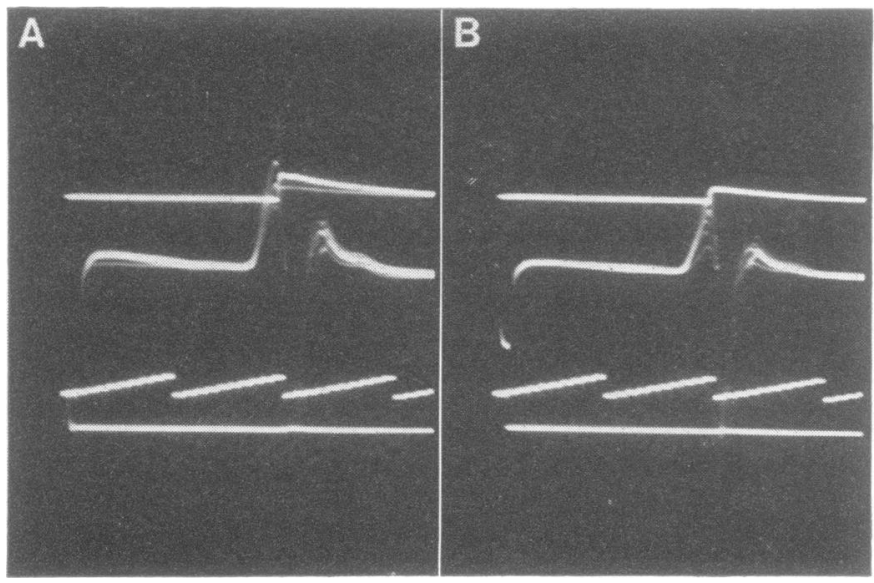

FIG. 1 Indirect motor responses derived from the flexor carpi radialis muscle after percutaneous electrical stimulation of the median nerve in the cubital fossa. There are 10 superimposed recordings with an electrical stimulus strength which is subliminal for the direct motor response. The amplitude marker, indicated in the upper trace, means $100 \mu \mathrm{V}$ in both photographs. The duration of the electrical stimulus is $1.0 \mathrm{~ms}$ and is shown in the lower trace. The latency in both photographs remains remarkably stable $(16.5 \mathrm{~ms})$. 

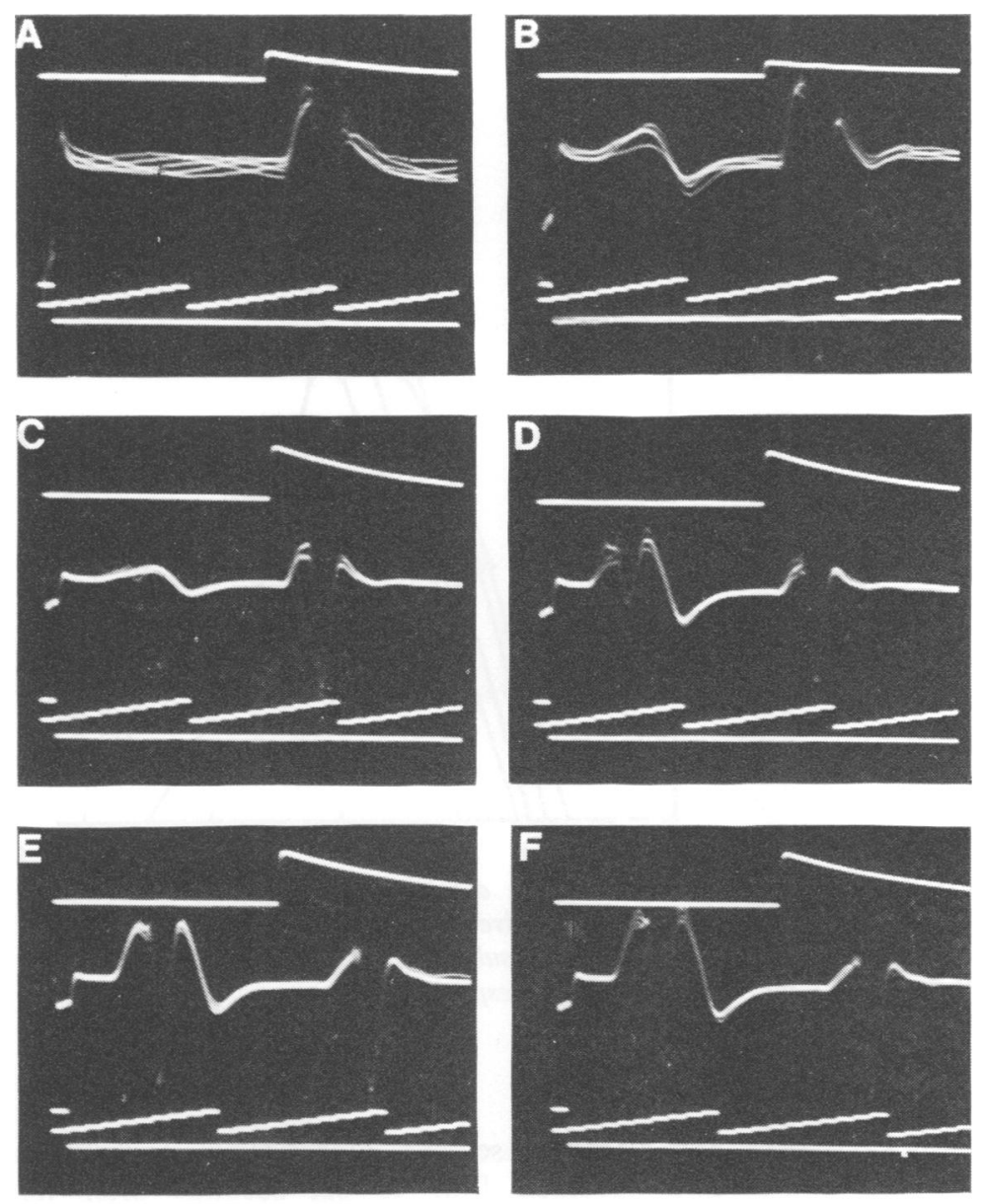

FIG. 2 Indirect and direct motor responses in the flexor carpi radialis muscle during percutaneous electrical stimulation with increasing intensity. The sequence of events (see text) is comparable with that described for the soleus muscle. The arrangement is the same as in Fig. 1. The amplitude calibration is $100 \mu V$ in $A$ and $B$, and $1000 \mu V$ in the following photographs.
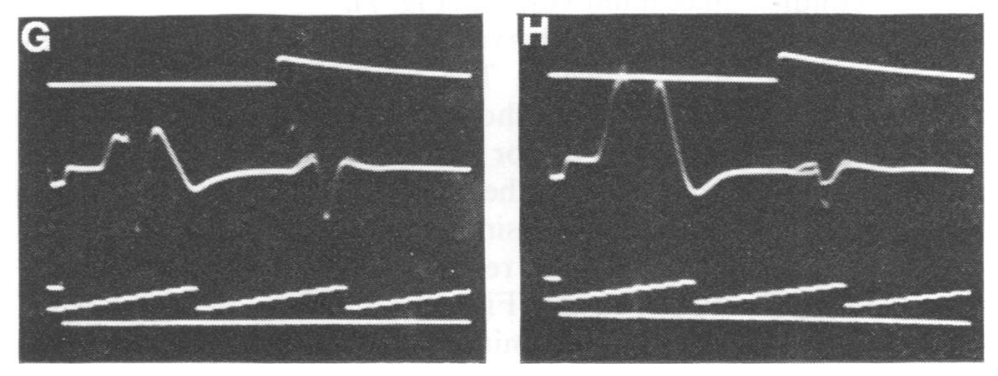

is a shift to the left of the $M$ wave curve when compared with the classical recruitment curves described for the soleus muscle (Hugon, 1973). Variations of the $M$ wave curve in one subject are demonstrated in Fig. 4 with an invariable IMR ( $H$ wave) curve. Slight displacements of the stimulating electrode may provoke these varia- tions and the shift to the left of the $M$ wave curve may be more accentuated.

The study of the recruitment curves indicated that the maximal amplitude of the IMR was reached with an intensity of the ES that evoked a DMR of about the same amplitude. The control of a quasi-invariable DMR of such an amplitude 


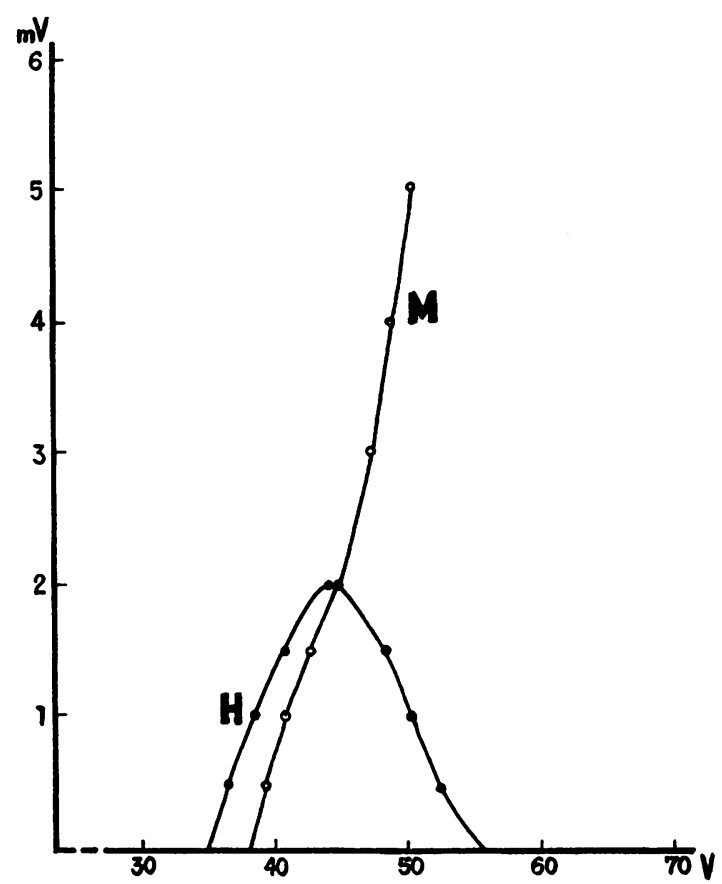

FIG. 3 Typical recruitment curves of the direct and indirect motor responses in the flexor carpi radialis muscle in a normal subject. One point represents the mean value of 10 measurements. Ordinate: amplitude in millivolts. Abscissa: intensity of the electrical stimulus in volts.

was used to maintain a stable experimental condition (Fig. 5) when vibration was applied to the tendon. Special attention was paid to ensure isometric contractions during vibratory stimulation. The effects of vibratory stimulation are illustrated in Fig. 6. During vibration of the tendon of the FCR muscle the IMR disappeared almost immediately and completely in all of the subjects. The complete abolition of the IMR was not surprising when detecting with a coaxial needle electrode as earlier experiments with such an electrode inserted in the medial gastrocnemius muscle furnished identical data. When vibration was stopped, the $\mathbf{H}$ wave reappeared within one second, and in most instances the $H$ wave amplitude reached the initial voltage one second after the cessation of the vibratory stimulus. Thereafter, a rebound effect was usually observed and the maximum rebound effect was commonly

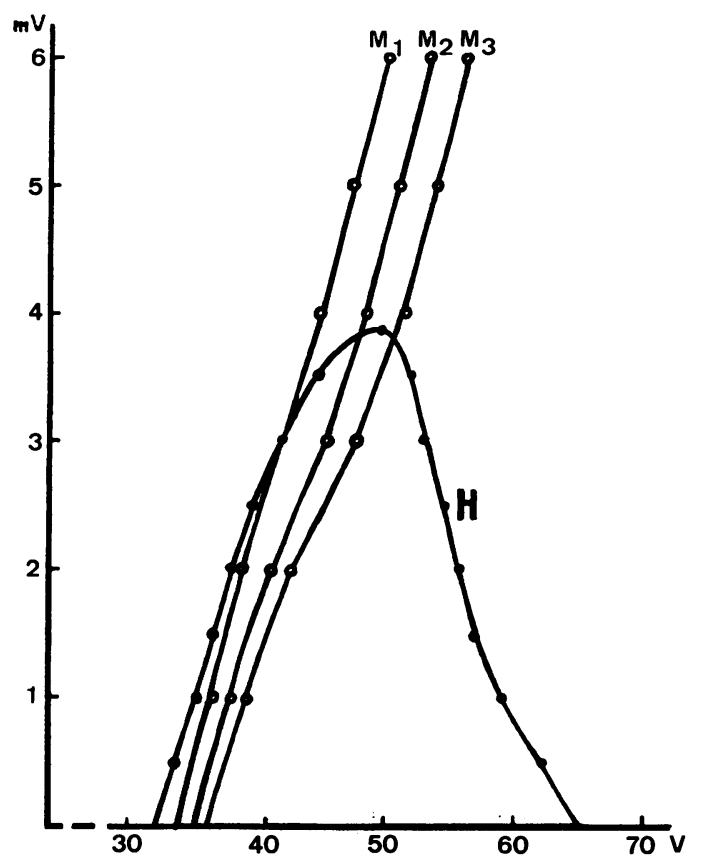

FIG. 4 Slight displacements of the stimulating electrode may give different curves of the direct motor response in one subject with an invariable curve of the indirect motor response. The arrangement is the same as in Fig. 3.

seen after three seconds, then it declined gradually and subsided four to six seconds after its maximum voltage (Fig. 7).

Recovery curves of the IMRs were constructed in 15 subjects. The electrical stimulus strength was near-threshold or slightly supraliminal for a direct motor response (Fig. 8). Figure 8 demonstrates the initial facilitation phase. There was a striking similarity between the typical and representative recovery curve derived from the FCR muscle (Fig. 9) and those recorded from the gastrocnemius-soleus muscles. There is no need to repeat the distinctive phases of the classical recovery cycles and what they are ascribed to (Magladery et al., 1952; Olsen and Diamantopoulos, 1967; McLeod, 1969). The late phase of recovery was found to be a phase of depression in all subjects.

Isometric and isotonic contractions of the ipsilateral quadriceps muscle without any concomitant activation of the forearm flexors substantially 
1

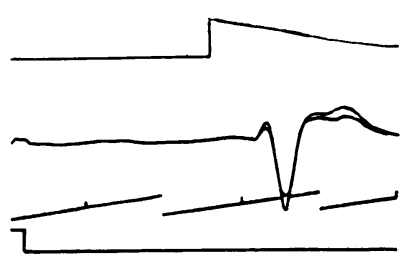

2
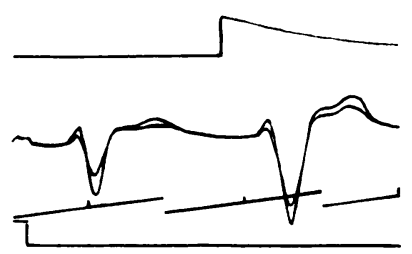

3

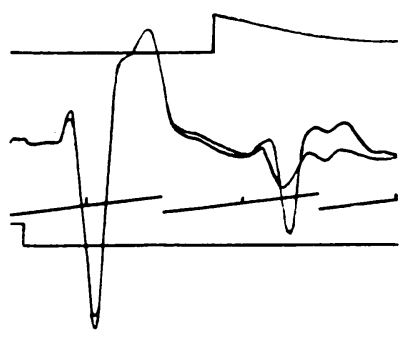

4

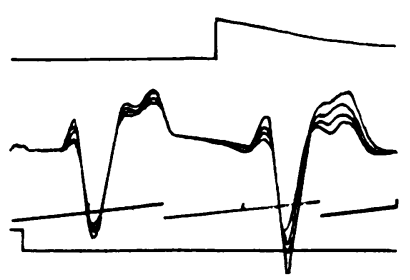

FIG. 5 Control of a quasi-invariable direct motor response in the presence of an indirect motor response of about the same amplitude (see Fig. 2, E and F). Amplitude marker: $1000 \mu \mathrm{V}$.

reinforced the IMRs. In 15 subjects an increase of $50-100 \%$ of the amplitude was observed with the previously mentioned technique of controlled stable DMRs. With an intensity of the ES which was threshold for the DMRs a greater enhancement of the amplitude of the IMRs was currently seen.

Tetanic stimulation of the median nerve, causing a tonic contraction of the forearm flexors, clearly potentiated the IMRs derived from the FCR muscle, with a maximum effect

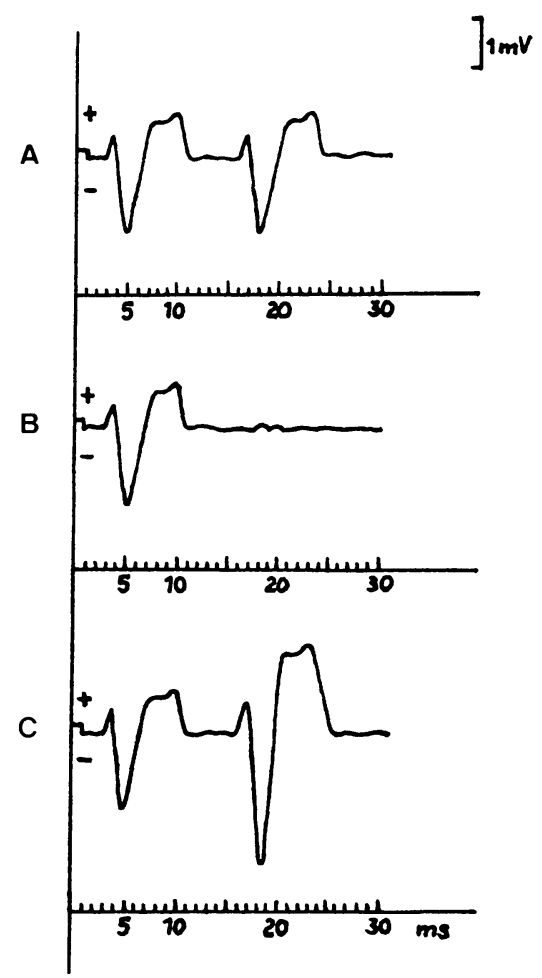

FIG. 6 The effects of vibration of the tendon of the flexor carpi radialis muscle on the direct and indirect motor responses elicited in this muscle. The effects of postvibratory potentiation observed for the indirect motor responses recorded from the same muscle. $A$ : control $M$ - and $H$-waves. B: vibration applied to the tendon. $C: M$ - and $H$-waves after the cessation of vibration; rebound effect.

five to 10 seconds after the end of the tetanus. The increase of the IMR amplitude may reach $50-75 \%$, if the ES strength was threshold for the DMRs. Post-tetanic potentiation declined after 10 seconds and usually subsided completely 20 seconds later.

Considering mechanically induced reflex responses, one should remember that the monosynaptic pathway of the tendon jerk response and the $\mathrm{H}$ reflex in the soleusgastrocnemius muscles has been well established in normal subjects (Magladery et al., 1951). Although they use identical pathways, the $\mathbf{H}$ and tendon jerk reflexes apparently are not true counterparts of each other (Herman, 1969). Moreover, in subjects with brisk 


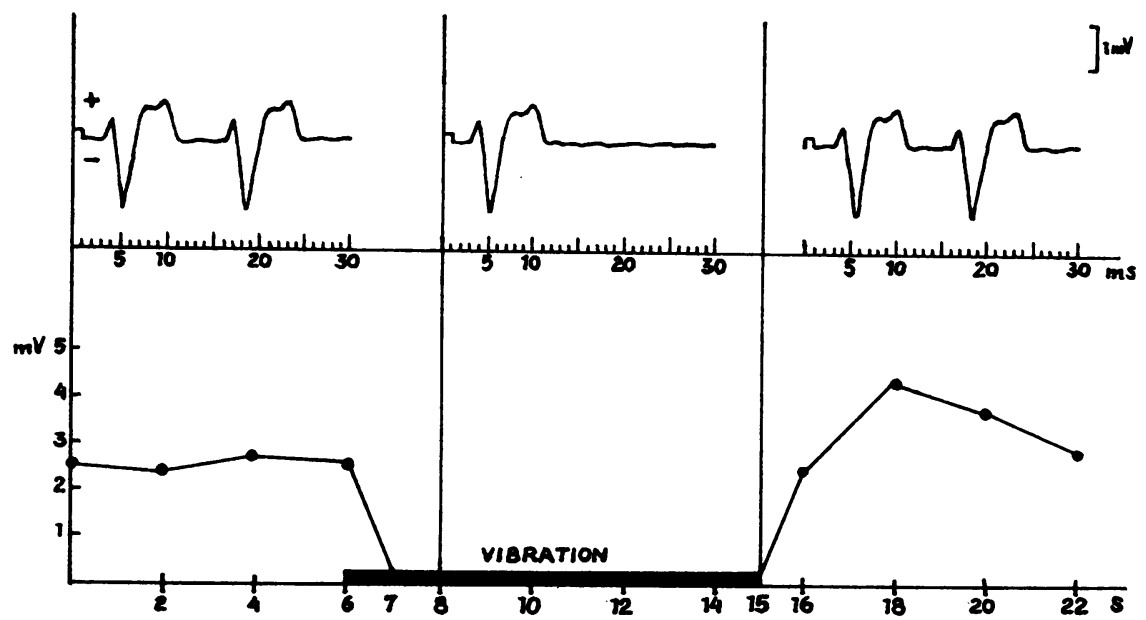

FIG. 7 Time course of the effects of vibratory stimulation of the tendon on the indirect motor responses recorded from the flexor carpi radialis muscle. Abscissa: duration of vibration is indicated as a heavy black line.
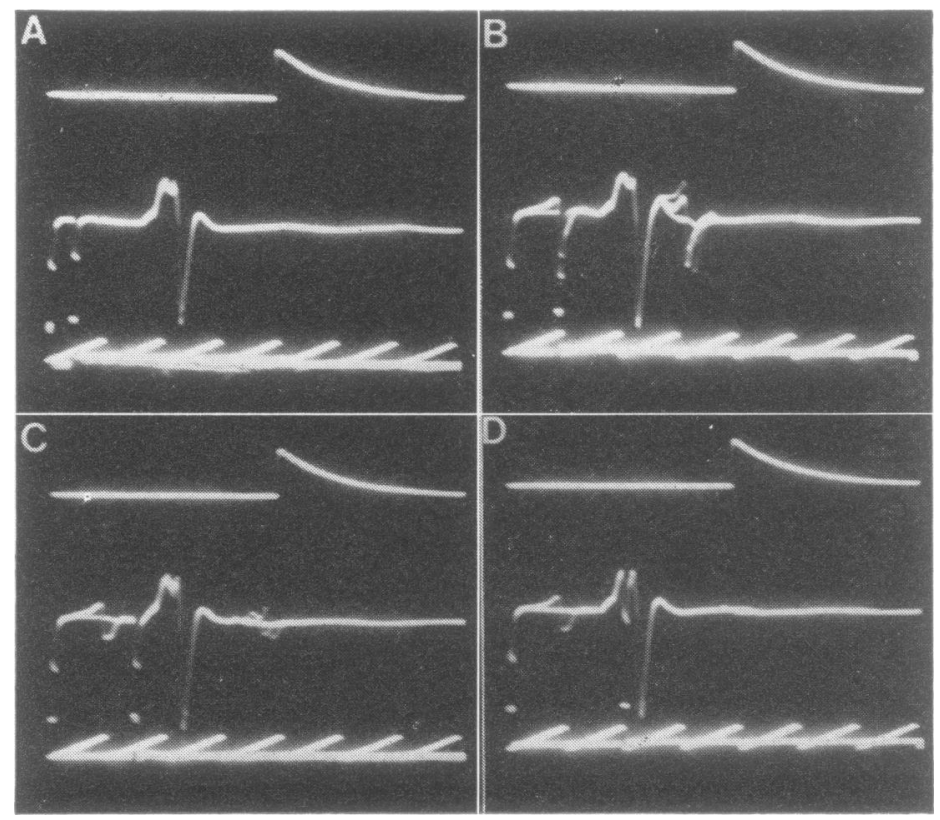

FIG. 8 This series of photographs demonstrates the initial facilitation phase of the recovery cycle. Paired stimuli of equal strength and identical duration $(1.0 \mathrm{~ms})$ were delivered to the median nerve with an increasing interval between the conditioning and the test stimulus (4 ms; $9 \mathrm{~ms} ; 14 \mathrm{~ms}$; $19 \mathrm{~ms}$ ). Amplitude marker: $1000 \mu \mathrm{V}$. 


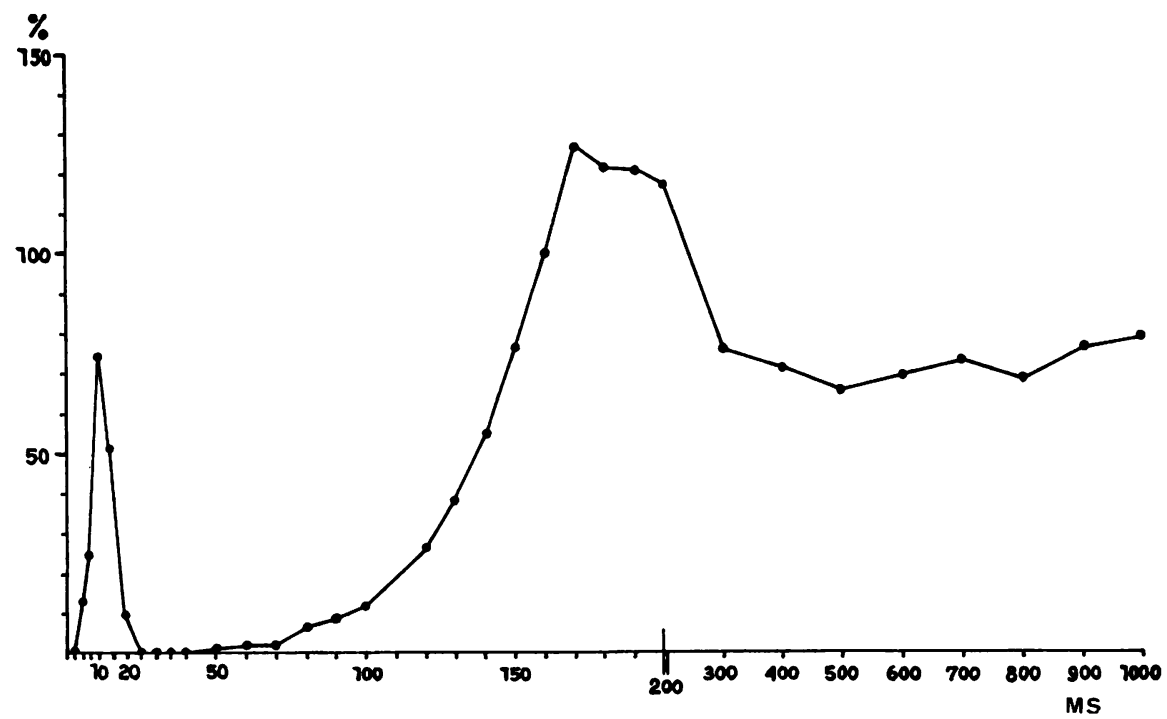

FIG. 9 Typical recovery curve for the indirect motor response recorded from the flexor carpi radialis muscle in a normal subject. Mean values of five trials. Ordinate: ratio of amplitude of test response to amplitude of conditioning response. Abscissa: interval between conditioning and test stimuli.

stretch reflexes, a blow to the Achilles tendon may produce a contraction of the ipsilateral hamstring muscles together with the triceps surae. Occasionally other muscles may also respond-for example, the ipsilateral quadriceps muscle and the contralateral thigh adductors and knee flexors - and this was termed reflex irradiation or spread of phasic muscle reflexes (Lance and De Gail, 1965). An analogous reflex irradiation is found in the upper limb by the direct bone percussion of the styloid process of the radius - that is, the brachioradialis reflex and the accompanying contraction of other muscles-apart from the superficial forearm flexors, the remote contractions of biceps brachii, pectoralis major, triceps brachii, and finger flexors in susceptible subjects (Lance and De Gail, 1965; Lance et al., 1973). It seems likely that the stretch stimulus is transmitted mechanically to the receptors of other muscles through the skeletal structures of the limb to adjacent regions as a vibration wave. Independent afferent nerve fibres producing these contractions were substantiated by differential blocking of the peripheral nerves (Lance and De Gail, 1965; Lance et al., 1973). In addition, Teasdall and Magladery (1974) provided evidence that after a blow to the styloid process of the radius, the latencies of the brachioradialis muscle response and the forearm flexors responses were identical in any one subject. In the same report the authors demonstrated in hemiplegics that $\mathbf{H}$ reflexes derived from the brachioradialis muscle and the forearm flexors, after stimulation of the appropriate nerves (radial and ulnar nerve), exhibited similar latencies. These findings, of course, lend support to the basic inference put forward above, that the brachioradialis reflex and the concomitant contractions of the forearm flexors resulted from independent myotatic reflexes. For comparative purposes we reinvestigated, with a blow to the styloid process, the latencies of the brachioradialis muscle reflex and of the accompanying reflex contractions of the FCR and PL muscles. If selective tendon tap of these forearm flexors was performed, the latencies were similar to those obtained after the percussion of the styloid process of the radius. Finally, the latencies of the IMRs derived from the superficial forearm flexors were similar to the latencies obtained after selective tendon tap and after the brachioradialis reflex.

An account of the patients examined will be given in broad outline to stress some basic principles as they are conceived by the authors. 
Measurements of the latency of IMRs in the FCR and PL muscles offer a diagnostic tool for chronic compression syndromes. This was found in the chronic compression of the $\mathrm{C} 7$ nerve roots, middle trunks, and medial cords of the brachial plexus, the affected side being compared with the contralateral side. In chronic lesions, and even in more acute lesions, the absence of the IMRs, or a reduced amplitude of these responses compared with the unaffected side, may indicate a more selective involvement of the Ia afferent fibres when no appreciable motor fibre loss could be disclosed. In generalized peripheral neuropathies latency measurements of the $H$ reflexes are proposed as a supplementary investigation, particularly in alcoholic polyneuropathies (Blackstock et al., 1972). In idiopathic polyneuropathy (Guillain-Barré-Strohl) extremely increased latencies have been observed in paretic limbs even at a time when the distal conduction velocities of motor and sensory fibres were not substantially decreased. Thus, measurements of the IMR latencies provide a prominent contribution to the early diagnosis of idiopathic polyneuropathy, when the upper limb is initially and primarily affected.

Vibration induced inhibition of the IMR was absent or reduced in spastic hyperreflexia of the upper limb. This was investigated in 20 hemiplegics and usually correlated with the degree of spastic paralysis. It is of interest to recognize an early involvement of the upper motor neurones, for instance in limited cerebral cortex lesions or confined damage of the pyramidal tracts which affect the upper limb. Further, some neurological disorders involving the pyramidal tracts may predominantly disturb the upper extremity as we have found in pseudobulbar palsy, familial amyotrophic lateral sclerosis, and subacute combined degeneration of the spinal cord, when no noticeable hyperreflexia was present in the lower limbs.

\section{DISCUSSION}

For the characteristics of the $\mathrm{H}$ wave and the $F$ wave in normal adults the reader is referred to Hoffmann (1918), Magladery and McDougal (1950), Hagbarth (1962), Angel and Hofmann (1963), Mayer and Mawdsley (1965), Hagbarth and Eklund (1966), and Mayer and Feldman (1967). It has been concluded that the $\mathrm{H}$ wave is a monosynaptic response evoked by the electrical stimulation of the larger Ia afferent nerve fibres and that the $F$ wave consisted, partially at least, of recurrent discharges.

In this study secondary motor responses with only the characteristics of the $\mathrm{H}$ wave could be derived from the FCR muscle in 50 normal adults. Bilateral detection was performed in 20 subjects and, in addition, these late motor responses were recorded from the PL muscle in another 20 subjects. Detecting with needle electrodes, the IMRs could be elicited without any DMR, and when the intensity of the ES was increased the fluctuations of both responses followed the course of variation of the $\mathrm{H}$ and the $M$ wave derived from the medial gastrocnemius muscle (Deschuytere and Rosselle, 1971).

If the stimulating electrode was located more proximally, the latency of the IMR decreased; it of is clear that the spinal origin of the IMR is $\mathbb{D}$ on responsible for the decrease of the latency. When $\stackrel{\mathbb{\Omega}}{\stackrel{2}{2}}$ the stimulating electrode is positioned at the same $\overrightarrow{-}$ level, the configuration of the IMRs may vary, $\varnothing$ but the latencies did not change at all if the initial deflection was controlled, and this was $\overrightarrow{0}$ important for measuring latencies in chronic compression syndromes.

When the recruitment curves are considered one can notice the shift to the left of the DMR curve in the FCR muscle in comparison with the $M$ curve derived from the soleus muscle (Hugon, 1973). This may be explained partially by the differences of the respective diameters of the efferent and afferent fibres in the median nerve and in the tibial nerve. Some considerations on fibre size were presented in our previous papers (Deschuytere and Rosselle, 1971, 1973).

The complete abolition of the IMRs during vibration furnished a cogent argument for regarding these late motor responses as monosynaptic reflexes. Suppression of secondary motor responses has been reported only for monosynaptic reflex activity (Hagbarth and Eklund, 1966; Delwaide, 1973; Hagbarth, 1973; Lance et al., 1973). Further, it is known from animal experiments that the $F$ waves are not altered by vibratory stimulation (Lance et al., 1973), so it would be difficult to interpret the IMRs in the FCR muscle as F waves. Recording with coaxial 
needle electrodes the IMRs represent only the activity of a small bundle of muscle fibres. Complete disappearance of the IMR during vibration was probably due to the fact that a sufficient number of muscle spindle primary endings were quite easily activated, resulting in a prominent presynaptic inhibition of the motor neurones involved. Homonymous and heteronymous Ia collateral fibres play a role in presynaptic inhibition and the effects of antagonist muscles have to be taken in account (Lance et al., 1973). Intramuscular recording appeared to be more accurate for studying vibratory effects on the IMRs of the FCR muscle, as was observed for the $\mathrm{H}$ reflex in the medial gastrocnemius muscle. In this connection we have to propose an ES strength evoking triphasic DMRs and IMRs of equal amplitude which enabled us to maintain a stable experimental condition. Thus, with a DMR of constant voltage the variations of the IMRs reflected the fluctuations of excitability of the alpha motor neurones which was experienced when the subject was turning the head or moving the lower limbs, and real reinforcement manoeuvres increased the IMR amplitude up to $100 \%$.

The Jendrassik handgrip has been recognized as a genuine reflex facilitation. It was a matter of controversy whether there was a real contribution of fusimotor activation (gamma loop) under normal conditions. Alpha loop activation in reinforcement manoeuvres, producing a higher level of excitability of the alpha motor neurones, was demonstrated by Clare and Landau (1964) using the differential nerve block technique. Percutaneous recording from single human nerve fibres with tungsten electrodes, developed and described by Hagbarth and Vallbo (1967) and Vallbo and Hagbarth (1968), allows direct recording from Ia afferent fibres (Vallbo, 1973). Burg et al., (1974) observed a marked increase of muscle spindle afferent activity during a remote contraction-namely, in the tibial nerve during the Jendrassik manoeuvre and in the median nerve during a contraction of the ipsilateral quadriceps muscle. In this way forearm muscle spindle activation and tendon tap reinforcement were shown for the FCR and PL muscles. We were able to demonstrate reflex reinforcement in both forearm flexors utilizing the IMRs in 15 subjects and, detecting with needle electrodes, we never observed accompanying action potentials. The data of Burg et al. (1974) indicated that there is accelerated spindle activity in completely relaxed muscles during remote contractions, and the authors assumed that these findings constituted one piece of evidence for the contribution of the fusimotor system to the reinforcement of phasic reflexes. On the other hand, Hagbarth et al. (1975) described EMG signs of unintentional contractions occurring in the receptor-bearing muscle during reinforcement manoeuvres. Whether the increased spindle activity is associated with a voluntary contraction or not, $\mathrm{H}$ reflexes are likely to be facilitated through the gamma loop and the alpha loop during reinforcement manoeuvres, and it is known that $\mathrm{H}$ reflexes are indeed enhanced during slight active contraction of the muscle involved (Hoffmann, 1918).

Post-tetanic potentiation of mechanically and electrically induced monosynaptic reflexes has been demonstrated by Hagbarth (1962) in normal man. For technical reasons we have investigated only five subjects, and found that the IMRs of the FCR and PL muscles consistently increased in amplitude with a maximum effect five to 10 seconds after the end of the tetanus. From animal experiments it was concluded that post-tetanic potentiation was a state of long-lasting facilitation of presynaptic origin, based on a property obviously residing in the afferent nerve terminals and synaptic knobs (Lloyd, 1949; Eccles and Rall, 1951; Granit, 1956; Eccles and Krnjevic, 1959). It seems likely that identical mechanisms may operate at the spinal cord level in man. Since $F$ waves are identified in humans as recurrent discharges in motor fibres, it is inconceivable that the IMRs derived from the superficial forearm flexors, so firmly potentiated by tetanization, should be regarded as $F$ reflexes.

In view of what has been said previously about the brachioradialis reflex, it is of some interest to remember that the stretch stimulus is transmitted mechanically through skeletal structures as a vibration wave (Lance et al., 1973). Hence, the responses in different adjacent muscles, which are clearly demonstrated to be monosynaptic reflexes (Lance and De Gail, 1965; Teasdall and Magladery, 1974), are probably due to the first deflection, with the largest amplitude, of the vibration of the radius after the blow to the 
styloid process. This explanation agrees with the fact that sinusoidal vibration of the tendon may provoke a phasic spike in some susceptible subjects and more prominently in some spastics, when the vibrator is switched on. Although the tonic vibration reflex develops progressively and appears to be desynchronized with the vibration cycles, one should take account of a possible monosynaptic reflex component together with a polysynaptic one (Hagbarth, 1973; Lance et al., 1973). The findings of Godaux and Desmedt (1975) for the human masseter muscle also indicate that the tonic vibration reflex involves both a monosynaptic and a polysynaptic reflex pathway.

As far as recovery curves are concerned, the distinctive phases of facilitation and inhibition of the conditioned reflex response in the FCR and PL muscles were comparable with those found in the calf muscles, revealing, apart from being an argument for the monosynaptic nature of the IMRs, that these superficial forearm flexors behave as physiological extensors. Indeed, in all of the 15 subjects, a prominent inhibition was consistently seen during the late phase of the excitability cycle. In animal experiments this late period of the recovery curve was reported to be due to the influences of group II afferent fibres, being inhibitory for an extensor and excitatory for a flexor muscle (Bianconi et al., 1964a, b; Granit et al., 1966), and it was assumed by McLeod (1969) that the same inhibitory effects of group II afferent fibres may operate in man.

In conclusion, it can be said that some of our experiments constitute circumstantial arguments for the monosynaptic nature of the IMR and that most of our observations support the view that these IMRs are to be considered as genuine $\mathbf{H}$ reflexes as described for the gastrocnemiussoleus muscles. Moreover, the findings in the pathological conditions studied turned out to be in keeping with such a point of view. The clinical significance of the method has to be stressed and it is to be hoped that its simplicity and the invaluable information that it affords will lead to the very frequent use of these examinations.

\section{REFERENCES}

Angel, R. W., and Hofmann, W. W. (1963). The H reflex in normal, spastic and rigid subjects. Archives of Neurology (Chic.), 8, 591-596.
Bianconi, R., Granit, R., and Reis, D. J. (1964a). The effects of extensor muscle spindles and tendon organs on homonymous motoneurones in relation to $\gamma$-bias and curarization. Acta Physiologica Scandinavica, 61, 331-347.

Bianconi, R., Granit, R., and Reis, D. J. (1964b). The effects of flexor muscle spindles and tendon organs on homonymous motoneurones in relation to $\gamma$-bias and curarization. Acta Physiologica Scandinavica, 61, 348-356.

Blackstock, E., Rushworth, G., and Gath, D. (1972). Electrophysiological studies in alcoholism. Journal of Neurology, Neurosurgery, and Psychiatry, 35, 326-334.

Burg, D., Szumski, A. J., Struppler, A., and Velho, F. (1974). Assessment of fusimotor contribution to reflex reinforcement in humans. Journal of Neurology, Neurosurgery, and Psychiatry, 37, 1012-1021.

Clare, M. H., and Landau, W. M. (1964). Fusimotor function. Part V. Reflex reinforcement under fusimotor block in normal subjects. Archives of Neurology (Chic.), 10, 123-127.

Delwaide, P. J. (1973). Human monosynaptic reflexes and presynaptic inhibition. An interpretation of spastic hyperreflexia. In New Developments in Electromyography and Clinical Neurophysiology, vol. 3, pp. 508-522. Edited by J. E. Desmedt. Karger: Basel.

Deschuytere, J., and Rosselle, N. (1971). Identification of certain EMG patterns of the spinal cord reflexive activity in man. Electrophysiological study of discharges from spinal origin in the anterolateral muscles of the leg in normal adults. Electromyography (Louvain), 11, 331-363.

Deschuytere, J., and Rosselle, N. (1973). Diagnostic use of monosynaptic reflexes in L5 and S1 root compression. In New Developments in Electromyography and Clinical Neurophysiology, vol. 3, pp. 360-366. Edited by J. E. Desmedt. Karger: Basel.

Deschuytere, J., and Rosselle, N. (1974). Identification of certain EMG patterns of the spinal cord reflexive activity in man. Electrophysiological study of discharges from spinal origin in the forearm flexors in normal adults. Electromyography and Clinical Neurophysiology, 14, 497-511.

Deschuytere, J., and Rosselle, N. (1975). Clinical uses of the proprioceptive reflexes in the superficial forearm flexors. (Abstract.). Electroencephalography and Clinical Neurophysiology, 39, 301.

Eccles, J. C., and Krnjevic, K. (1959). Presynaptic changes associated with post-tetanic potentiation in the spinal cord. Journal of Physiology, 149, 274-287.

Eccles, J. C., and Rall, W. (1951). Effects induced in a monosynaptic reflex path by its activation. Journal of Neurophysiology, 14, 353-375.

Godaux, E., and Desmedt, J. E. (1975). Evidence for a monosynaptic mechanism in the tonic vibration reflex of the human masseter muscle. Journal of Neurology, Neurosurgery, and Psychiatry, 38, 161-168. 
Granit, R. (1956). Reflex rebound by post-tetanic potentiation. Temporal summation-spasticity. Journal of Physiology, 131, 32-51.

Granit, R., Kellerth, J. O., and Szumski, A. J. (1966). Intracellular autogenetic effects of muscular contraction on extensor motoneurones. The silent period. Journal of Physiology, 182, 484-503.

Hagbarth, K. E. (1962). Post-tetanic potentiation of myotatic reflexes in man. Journal of Neurology, Neurosurgery, and Psychiatry, 25, 1-10.

Hagbarth, K. E. (1973). The effects of muscle vibration in normal man and in patients with motor disorders. In New Developments in Electromyography and Clinical Neurophysiology, vol. 3, pp. 428-443. Edited by J. E. Desmedt. Karger: Basel.

Hagbarth, K. E., and Eklund, G. (1966). Motor effects of vibratory stimuli in man. In Muscular Afferents and Motor Control. Nobel Symposium I, pp. 177-186. Edited by R. Granit. Almqvist and Wiksell: Stockholm.

Hagbarth, K. E., and Vallbo, A. B. (1967). Mechanoreceptor activity recorded percutaneously with semimicroelectrodes in human peripheral nerves. Acta Physiologica Scandinavica, 69, 121-122.

Hagbarth, K. E., Wallin, G., Burke, D., and Lofstedt, L. (1975). The effects of Jendrassik's manoeuvre on muscle spindle activity in man. V International Congress of Electromyography, Rochester, Minnesota. Abstracts of Communications, p. 27.

Herman, R. (1969). Relationship between the $H$ reflex and the tendon jerk response. Electromyography (Louvain), 4, 359-370.

Hoffmann, P. (1918). Uber die Beziehungen der Sehnenreflexe zur willkürlichen Bewegung und zum Tonus. Zeitschrift für Biologie, 68, 351-370.

Hugon, M. (1973). Methodology of the Hoffmann reflex in man. In New Developments in Electromyography and Clinical Neurophysiology, vol. 3, pp. 277-293. Edited by J. E. Desmedt. Karger: Basel.

Lance, J. W., and De Gail, P. (1965). Spread of phasic muscle reflexes in normal and spastic subjects. Journal of Neurology, Neurosurgery, and Psychiatry, 28, 328-334.

Lance, J. W., Burke, D., and Andrews, C. J. (1973). The reflex effects of muscle vibration. In New Developments in Electromyography and Clinical Neurophysiology, vol. 3, pp. 444-462. Edited by J. E. Desmedt. Karger: Basel.

Lloyd, D. P. C. (1949). Post-tetanic potentiation of response in monosynaptic reflex pathways of the spinal cord. Journal of General Physiology, 33, 147-170.
McLeod, J. G. (1969). H reflex studies in patients with cerebellar disorders. Journal of Neurology, Neurosurgery, and Psychiatry, 32, 21-27.

Magladery, J. W., and McDougal, D. B. (1950). Electrophysiological studies of nerve and reflex activity in normal man. I. Identification of certain reflexes in the electromyogram and the conduction of peripheral nerve fibres. Bulletin of the Johns Hopkins Hospital, 86, 265-290.

Magladery, J. W., Porter, W. E., Park, A. M., and Teasdall, R. D. (1951). Electrophysiological studies of nerve and reflex activity in normal man. 4. The two neurone reflex and identification of certain action potentials from spinal roots and cord. Bulletin of the Johns Hopkins Hospital, 88, 499-519.

Magladery, J. W., Teasdall, R. D., Park, A. M., and Languth, H. W. (1952). Electrophysiological studies of reflex activity in patients with lesions of the nervous system. 1. A comparison of spinal motoneurone excitability following afferent nerve volleys in normal persons and patients with upper motor neurone lesions. Bulletin of the Johns Hopkins Hospital, 91, 219-244.

Mayer, R. F., and Feldman, R. G. (1967). Observations on the nature of the $\mathrm{F}$ wave in man. Neurology (Minneap.), 17, 147-156.

Mayer, R. F., and Mawdsley, C. (1965). Studies in man and cat of the significance of the $\mathrm{H}$ wave. Journal of Neurology, Neurosurgery, and Psychiatry, 28, 201-211.

Olsen, P. Z., and Diamantopoulos, E. (1967). Excitability of spinal motor neurones in normal subjects and patients with spasticity, Parkinsonian rigidity and cerebellar hypotonia. Journal of Neurology, Neurosurgery, and Psychiatry, 30, 325-331.

Simon, J. N. (1962). Dispositif de contention des électrodes de stimulation pour l'étude du réflexe de Hoffmann chez l'homme. Electroencephalography and Clinical Neurophysiology, suppl. 22, 174-176.

Teasdall, R. D., and Magladery, J. W. (1974). Brachioradialis reflex and contraction of forearm flexors. Archives of Neurology (Chic.), 30, 94-95.

Vallbo, §. B. (1973). Muscle spindle afferent discharge from resting and contracting muscles in normal human subjects. In New Developments in Electromyography and Clinical Neurophysiology, vol. 3, pp. 251-262. Edited by J. E. Desmedt. Karger: Basel.

Vallbo, Å. B., and Hagbarth, K. E. (1968). Activity from skin mechanoreceptors recorded percutaneously in awake human subjects. Experimental Neurology, 21, 270-289. 